\title{
A retrospective review of an epidural blood patch database in a tertiary maternity unit in Greece.
}

Kalopita K, Skandalou V, Loukeri A, Stamatakis E, Hadzilias S, Papas M, Valsamidis D.

\section{Department of Anaesthesiology and Pain Medicine "Alexandra" General Hospital of Athens, Greece.}

\section{Background and aims}

Accidental Dural puncture (ADP) is often associated with post-dural puncture headache (PDPH) in parturients. Although conventional treatment versus epidural blood patch (EBP) has been extensively reviewed, there is no consensus on the overall patient management.

\section{Methods}

We report a retrospective analysis of 116 parturients posted for caesarean section (CS) (108) or vaginal birth (VB) (8) who experienced ADP during Combined Spinal Epidural (CSE) or Epidural anaesthesia, while attending at a tertiary referral obstetric unit between January 2010 and December 2018. Patient records were reviewed for interventions, timing of EBP and outcome.
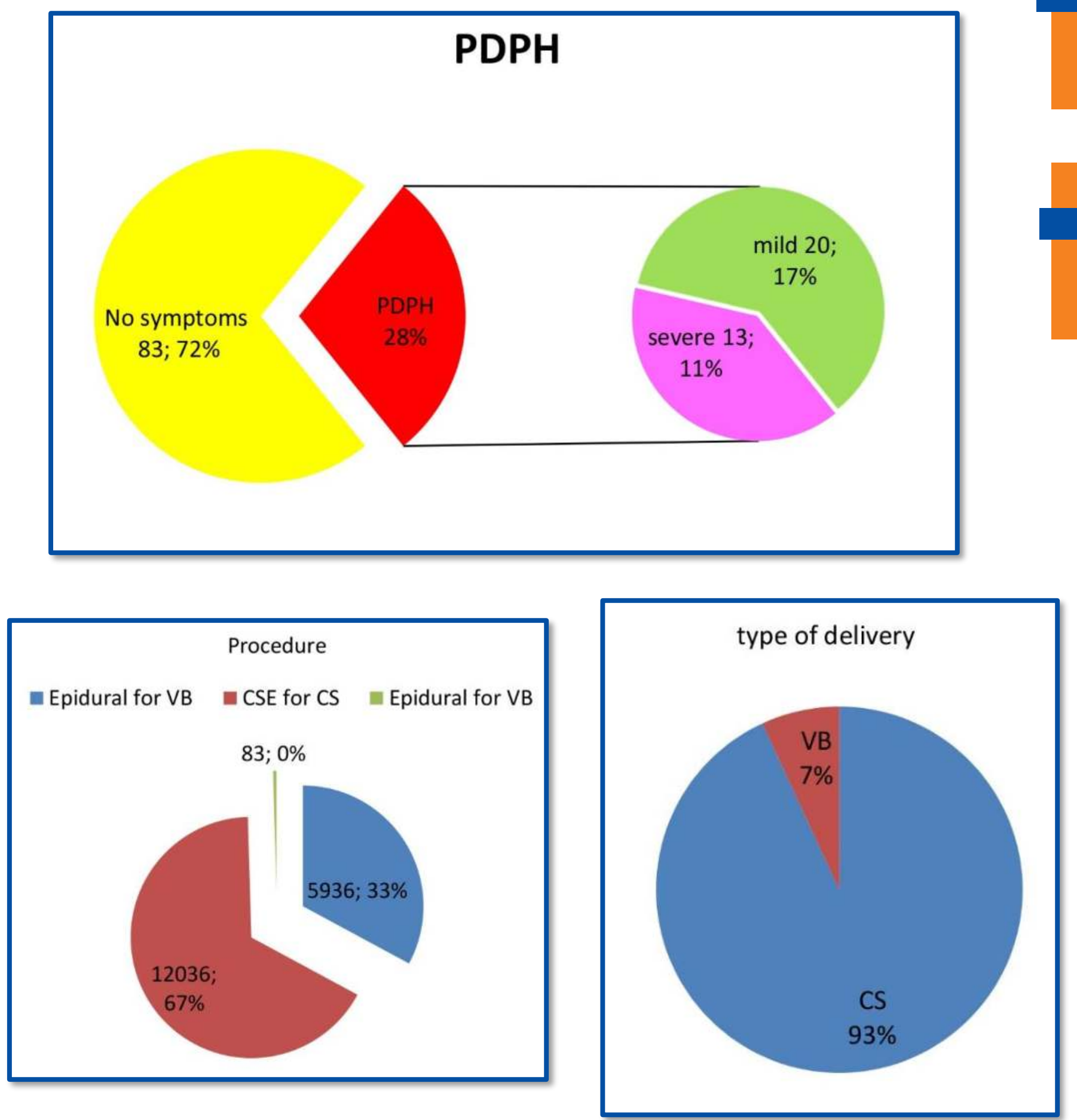

\section{Results}

During that period, we performed 5936 epidurals for VB, 12036 CSEs and 83 Epidurals for CS. The overall rate of ADP was $0.64 \%,(0.89 \%$ CS and $0.13 \% \mathrm{VB})$. The majority of ADPs (93) were reported during the identification of epidural space $(80.2 \%)$, whilst $20(17.2 \%)$ were recognized only after the withdrawal of the pencil-point needle or during the epidural catheter threading ( 1 - 0.9\%). In 2 cases, ADP was reported during local infiltration with the blue-hub (23G) needle. Among 34 parturients who experienced PDPH (29.3\%), 13 were classified as having experienced severe PDPH, whereas 20 as having mild. Only 11 patients consented to active treatment with an EBP. All EBPs were performed 48hrs after ADP. In 2 cases, a second EBP is reported due to an unresolved headache. The mean dose of blood injected was $21.72 \mathrm{ml}$ ( $\mathrm{min}$ $11 \mathrm{ml}$, max $40 \mathrm{ml}$ ). Follow-up was arranged in $100 \%$ of EBP patients.

\section{Conclusion}

EBP could be the most effective treatment for PDPH.

\section{References}

1. Van de Velde M, Schepers R, Berends N, Vandermeersch E, De Buck F. Ten years of experience with accidental dural puncture and post-dural puncture headache in a tertiary obstetric anaesthesia department. Int J Obstet Anesth. 2008 Oct; 17(4): 329-35.

2. Tien JC, Lim MJ, Leong WL, Lew E. Nine-year audit of post-dural puncture headache in a tertiary obstetric hospital in Singapore. Int $\mathrm{J}$ Obstet Anesth. 2016 Dec; 28: 34-38.

\begin{tabular}{|l|c|}
\hline Demographic data & \\
\hline Age, years mean (SD) & $31,3(5,4)$ \\
\hline Height, cm mean (SD) & $163,0(6,8)$ \\
\hline Weight before labour, mean (SD), (kgr) & $65,0(17,0)$ \\
\hline Weight on labour, mean (SD),(kgr) & $77,0(17,9)$ \\
\hline $\begin{array}{l}\text { Gestational age, wks median, (min-max) } \\
\{25 \%-75 \%\}^{1}\end{array}$ & $38(10-41)\{36-39\}$ \\
\hline
\end{tabular}

